\title{
PLEOMORPHIC ADENOMA OF MINOR SALIVARY GLAND IN BUCCAL MUCOSA: AN UNCOMMON FINDING
}

\section{Gourav Ahuja ${ }^{1}$, Jaideep Marya ${ }^{2}$, Poonam Sood ${ }^{3}$}

${ }^{1}$ Sr. Lecturer, Department of Oral and Maxillofacial Surgery, BRS Dental College and General Hospital, Haryana, India ${ }^{2}$ Assistant Professor, Department of Pathology, Government Medical College, Punjab, India

${ }^{3}$ Sr. Lecturer, Department of Public Health Dentistry, HSJ Institute of Dental Sciences and Research, Chandigarh, India

Sr. Lecture, Department of Public Health Dentistry, HSJ

\section{ABSTRACT}

Salivary gland tumors account for less than $3 \%$ of the head and neck tumors. Among various salivary gland tumors, pleomorphic adenoma is most common and accounts for $60-70 \%$ of the benign tumors of salivary glands. However, the involvement of minor salivary glands of buccal mucosa is extremely uncommon and reported to be $4 \%$ only. Salivary glands may present with a diverse range of lesions presenting a challenge to even the most experienced clinician. We report two rare cases of pleomorphic adenoma of minor salivary glands of buccal mucosa in a 45 year old female and 70 years old male respectively. It includes clinical features, diagnosis and treatment of the tumor.

Key words: Benign Pleomorphic Adenoma, Fine Needle Aspiration Cytology, Histopathology, Minor Salivary.

\section{INTRODUCTION}

Pleomorphic adenoma is defined by WHO as "a circumscribed tumor characterised by its pleomorphic or mixed appearance, clearly recognizable epithelial tissue being intermingled with tissue of mucoid, myxoid and chondroid appearance". ${ }^{1}$ It represents $3-10 \%$ neoplasms of the head and neck region. ${ }^{2,3}$ It is the most common benign neoplasm of the salivary glands. Among tumors of salivary glands, $60 \%$ are pleomorphic adenomas. ${ }^{4}$ Majority of these tumors occur in major salivary glands and only $6.5 \%$ in minor salivary glands. ${ }^{5}$ If the tumor occur in minor salivary gland the most common site is palate, but this tumor can also occur in other sites including the upper lip, buccal mucosa, floor of mouth, larynx and trachea. The review of literature reveals only $4 \%$ cases of pleomorphic adenoma of minor salivary glands occurring in the buccal mucosa. ${ }^{6}$ It occurs at all ages; however, commonly affected age groups are 5th and 6th decade. It is generally slow growing, painless and firm swelling. The covering mucosa is unaffected when minor salivary glands are involved. Majority of intraoral tumors are less than $3 \mathrm{~cm}$ in diameter. ${ }^{7,89}$

The purpose of this article is to report two cases of pleomorphic adenoma of minor salivary glands in buccal mucosa with the characteristic clinical, radiological, histological findings and treatment.

\section{Case Report 1}

A 45 years old female reported to the Department of Oral and Maxillofacial Surgery, Government Dental College and Hospital, Amritsar with the complain of painless, diffuse swelling of the left cheek region since one year (Figure 1). Past medical/dental history was not significant. On clinical examination, it revealed a freely mobile, well circumscribed, painless, oval swelling of size approximately $2 \mathrm{~cm}$ in diameter in the left buccal mucosa (Figure 2). The overlying mucosa and skin was of normal colour. The left ear lobule was not raised. No discharge or any secondary finding was present. On palpation, the swelling was non- tender, firm in consistency, nonfluctuant, non- reducible, compressible and non pulsatile. The temperature over the swelling was normal. The overlying 


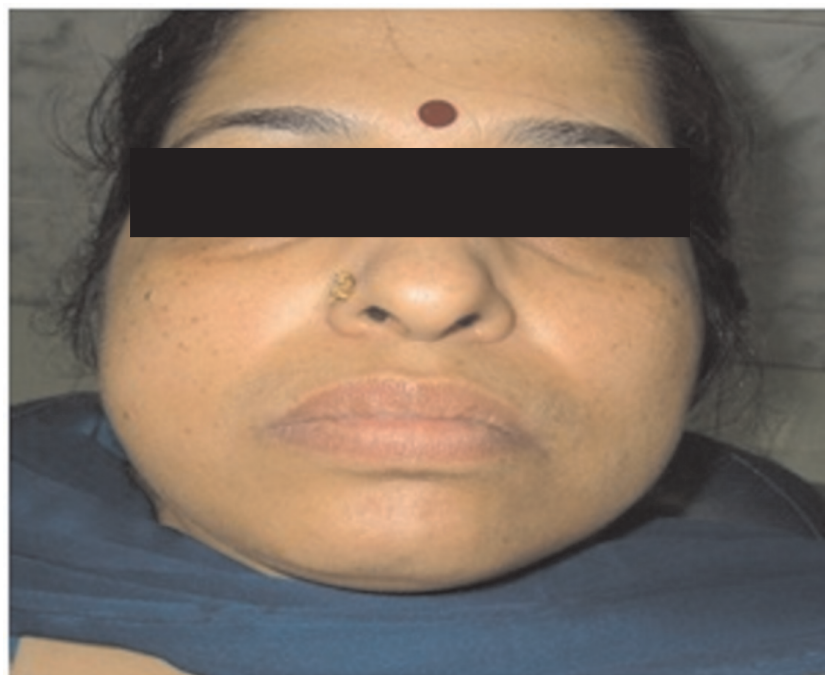

Figure 1: Extraoral photograph of the patient

mucosa and skin was not adherent to underlying mucosa.

Based on clinical findings, provisional diagnosis of lipoma of cheek was made. The patient was sent for Fine Needle Aspiration Cytology (FNAC). Report revealed angular cells in mucinous background. After FNAC the swelling suddenly increased in size and became painful. Patient was put on anti-inflammatory drugs for 5 days which reduced the swelling to its original size. Then excisional biopsy was done through the intra-oral mucosa. A well encapsulated circumscribed mass of $2 \mathrm{~cm} \times 2 \mathrm{~cm}$ in diameter was

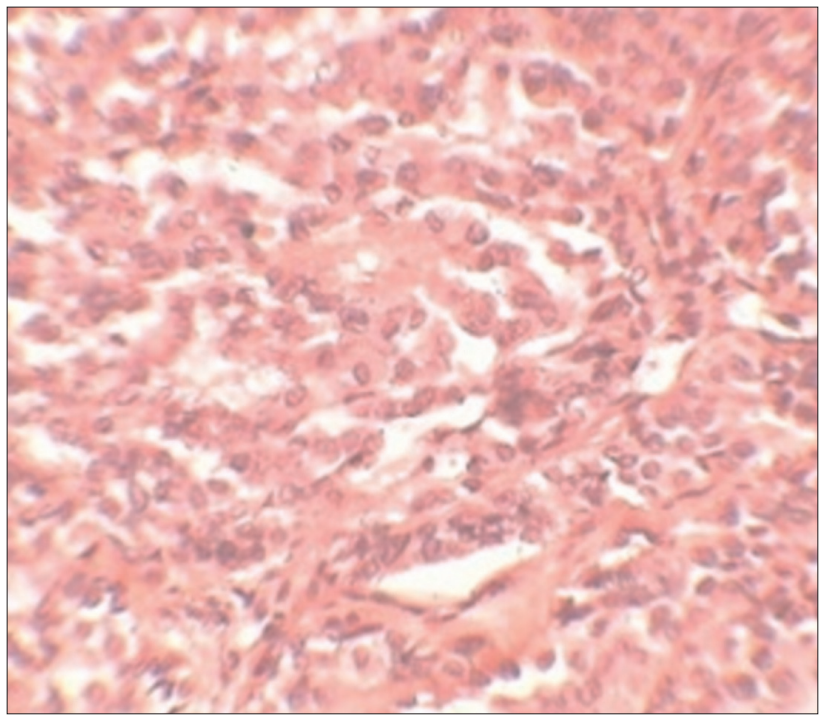

Figure 3: Histopathological image showing ductal pattern of epithelial cells

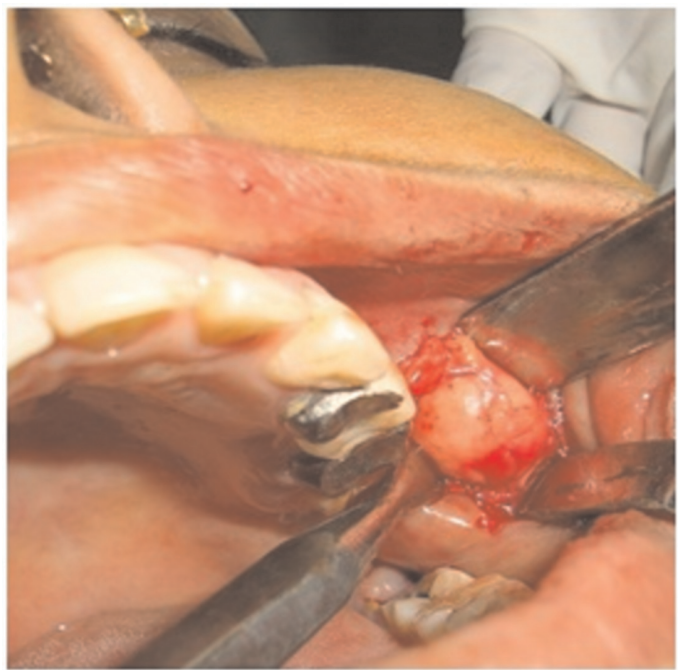

Figure 2: Intraoral clinical photograph revealing the extent of lesion

removed and sent for histopathological examination. Histological examination report gave the diagnosis of pleomorphic adenoma with the areas of infarction with viable stromal area at the periphery of the tumor (Figure 3). It also showed round to ovoid epithelial cells in myxomatous background.

\section{Case Report 2}

A 70 years old male reported with painless swelling in the right buccal region since one year. Clinical examination revealed a well circumscribed, painless nodule of $3 \mathrm{~cm} \times 3 \mathrm{~cm}$ in size (Figure 4). On palpation

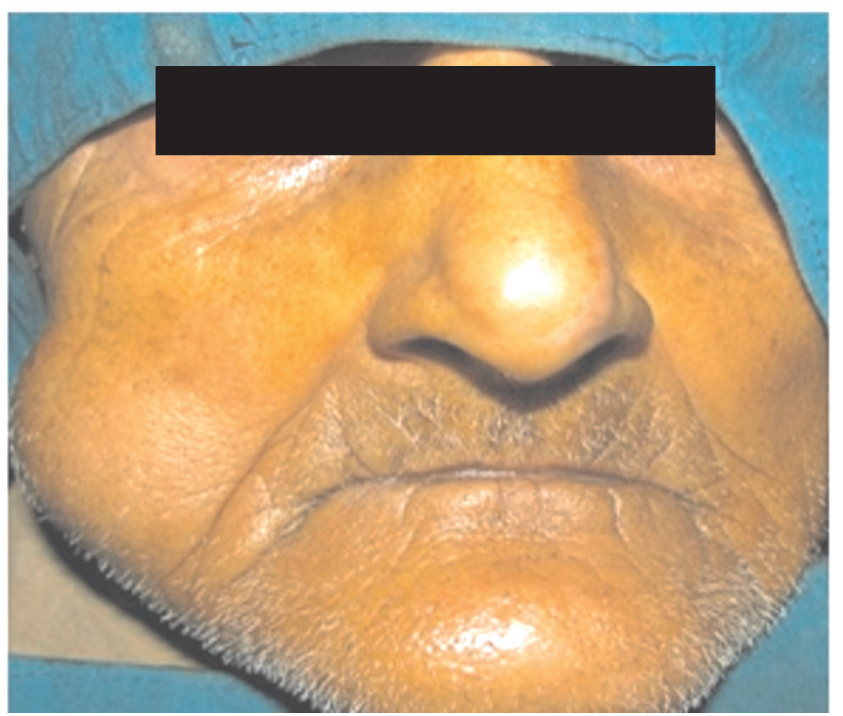

Figure 4: Extra oral photograph of the patient 
the swelling was non-tender, firm in consistency, nonfluctuant, non-reducible, compressible and nonpulsatile (Figure 5A). The temperature over the swelling was normal. The overlying skin and mucosa was normal in colour and texture and not adherent to underlying lesion. Lymph nodes were not palpable.

Patient was advised FNAC and findings revealed angular cells in mucinous background. The mass was enucleated by blunt dissection and it appeared to be encapsulated (Figure 5B). The specimen was sent for histopathological examination. The tissue section revealed mixture of glandular epithelium and myoepithelial cells with myxomatous background (Figure 6). These features confirmed the diagnosis of pleomorphic adenoma.

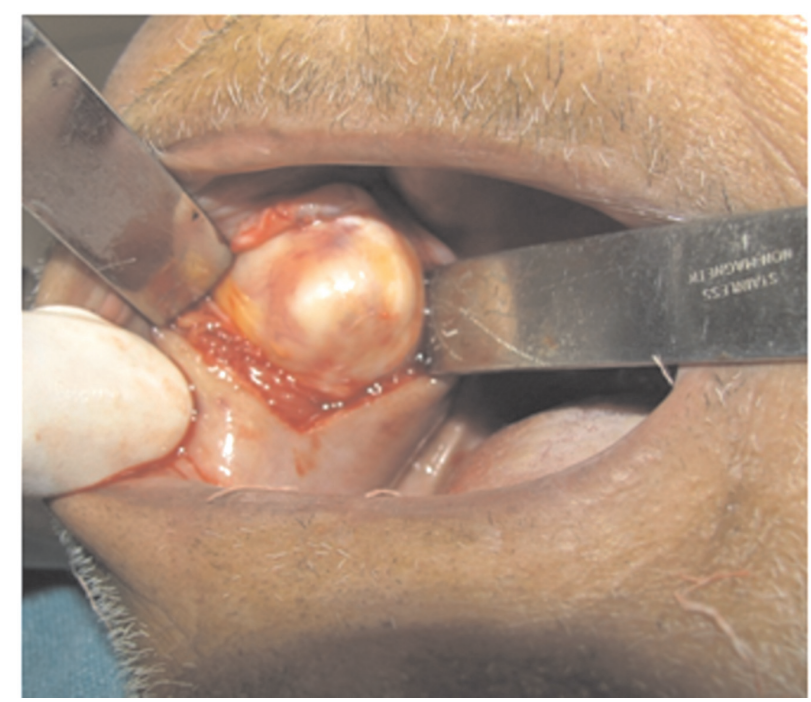

Figure 5A: Intraoral clinical photograph during excision of lesion

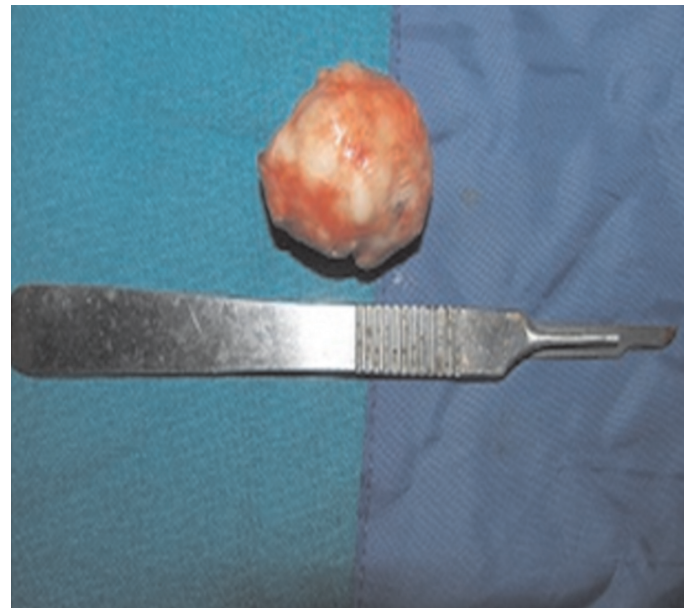

Figure 5B: Excised surgical specimen

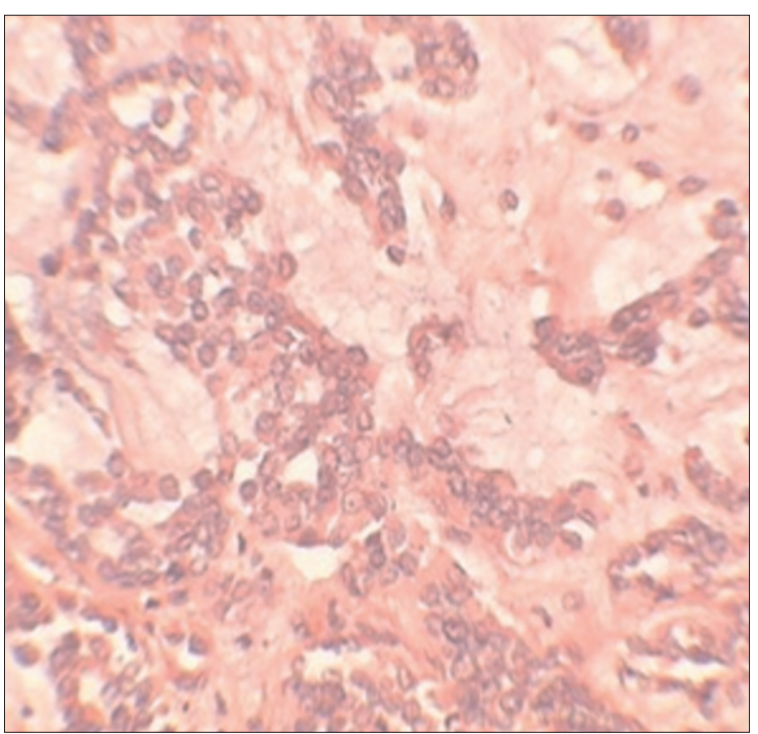

Figure 6: Histopathological image showing ductal pattern of epithelial cells

\section{DISCUSSION}

Tumors arising from the minor salivary glands account for $22 \%$ of all the salivary gland neoplasms. ${ }^{10}$ Majority are malignant and only $18 \%$ are benign. ${ }^{11}$ Among the benign tumors pleomorphic adenoma is most common. Palate is the most common site for pleomorphic adenoma (42-68\%), followed by lip (10\%), buccal $\operatorname{mucosa}(5.5 \%){ }^{8}$

Pleomorphic adenomas donot usually present sexual predisposition and they can appear at any age with same clinical behavior. They are generally round, slow growing tumors that are painless and firm in consistency. ${ }^{9}$ Those arising from the palate may cause discomfort to the patient while chewing and difficulty in speaking. The cases presented confer with the above findings.

FNAC has great value pre-operatively in differentiating between the inflammatory and neoplastic diseases of salivary glands. ${ }^{12}$ In one of our cases, infarction (ischemic necrosis) was seen histopathologically. Though necrosis of neoplastic tissue is considered to be a sign of malignancy but has been reported in literature in benign tumors including pleomorphic adenoma that have undergone fine needle aspiration cytology or surgical trauma. It is necessary to avoid mis-interpretation of ischemic necrosis as 
malignancy in an otherwise benign salivary gland neoplasm.

Microscopically, pleomorphic adenomas of minor salivary glands consists of epithelial cells and mesenchymal elements that tend to be more cellular, with less myxoid or chondroid component and located within the submucosa in contrast with tumors of the major salivary glands. ${ }^{13}$ Also, tumors of the minor salivary glands do not have a fibrotic capsule. They may have false infiltrative appearance. ${ }^{14}$ The same was seen in the cases reported in this article.

The treatment of pleomorphic adenoma is essentially surgical. ${ }^{11}$ Though these tumors are apparently well encapsulated, resection of the tumor with an adequate margin $(0.5-1.0 \mathrm{~cm})$ of grossly normal surrounding tissue is necessary to prevent local recurrence as these tumors are known to have microscopic pseudopod like extensions into the surrounding tissue due to dehiscences in the false capsule. ${ }^{15}$ Enucleation leads to recurrence. The prognosis will be excellent if resection is adequate. Irradiation is reserved for recurrences and inoperable cases. ${ }^{14}$ Malignant transformation has been reported (2$9 \%$ ), generally to adenocarcinoma or undifferentiated carcinoma. The risk of malignancy increases with the duration of the tumor and mean age of the patient. Regular follow- up is required.

\section{CONCLUSION}

Pleomorphic adenoma of minor salivary gland in buccal mucosa is a tumor of rare occurrence. Our report consists of 2 cases of pleomorphic adenoma of cheek region. The lesions were typical benign tumors, located between the cheek and the buccinator muscle. Fine needle aspiration cytology is a valuable diagnostic adjuvant in preoperative evaluation of salivary gland lesions. It provides preliminary diagnosis and preoperative assessment on which management decisions can be made. In the above reported cases, FNAC revealed pleomorphic adenoma which was confirmed histopathologically. High index of suspicion and an adequate clearance of the tumor with a cuff of surrounding dispensable normal tissues is the key to successful treatment of such tumors.

\section{ACKNOWLEDGMENT:}

The authors would like to acknowledge patients of the case report for their co-operation.

\section{REFERENCES}

1. Thacksrey AC and Sobin. Histological typing of salivary gland tumours. 1st ed. Geneva: World Health Organisation; 1972. p.1-18.

2. García Berrocal JR, Ramírez Camacho R, Trinidad A, Salas C. Mixed tumor (pleomorphic adenoma) of head and neck. Typical and atypical patterns. An Otorrinolaringol Ibero Am 2000; 27:333-40.

3. Moghe S, Pillai AK, Prabhu S, Nahar S, Kartika UK. Pleomorphic adenoma of the palate: Report of a case. Int J Sci Study 2014; 2: 54-6.

4. Dhanuthai K, Sappayatosok K, Kongin K. Pleomorphic adenoma of the palate in a child: a case report. Med Oral Patol Oral Cir Bucal 2009; 14: 73-5.

5. Smolka W, Eggensperger N, Stauffer- Brauch EJ, von Bredow F, Iizuka T. Pleomorphic adenoma in an atypical location near the temporomandibular joint. A case report. Qunitessence Int 2007; 38: 417- 21 .

6. Chidzonga MM, Lopez Perez VM, Portilla Alvarez AL. Pleomorphic adenoma of the salivary glands. Clinicopathologic study of 206 cases in Zimbabwe. Oral Surg Oral Med Oral Pathol Oral Radiol Endod 1995; 79: 747-49.

7. Vicente OP, Marqués NA, Aytés LB, Escoda CG. Minor salivary gland tumors: a clinicopathological study of 18 cases. Med Oral P Patol Oral Cir Bucal 2008; 13: 582-88.

8. Eisele DW, Johns ME. Salivary gland neoplasms. In: Bailey BJ, editor. Head and neck surgery-otolaryngology. 3rd ed. Philadelphia: Lippincott Williams \& Wilkins; 2001. p. 1279-97.

9. Dalati T, Hussein MR. Juvenile pleomorphic adenoma of the cheek: a case report and review of literature. Diagnostic Pathology 2009; 4: 1-5.

10. Thoeny HC. Imaging of salivary gland tumors. Cancer Imaging. 2007; 7: 52-62.

11. Hakeem AH, Hazarika B, Pradhan SA, Kannan R. Primary pleomorphic adenoma of minor salivary gland in the parapharyngeal space. World Journal of Surgical Oncology 2009; 7: 1-4.

12. Shashinder S, Tang IP, Velayutham P, Prepageran N, Gopala KG, Kuljit S. A review of Calponin, maspin, S-100 - Positive in parotid tumours and their management: A ten-yearexperience. Med J Malaysia 2009; 64: 31-3.

13. Speight PM. Update on diagnostic difficulties in lesions of the minor salivary glands. Head and Neck Pathol 2007; 1: 55-60.

14. De Paula Vernetta C, Garcia Callejo FJ, Ramirez Sabio JB, Orts Alborch MH, Morant Ventura A, Marco Algarra J. Giant pleopmorphic adenoma of minor salivary gland. Transoral. Rev Esp Cir Oral y Maxilofac 2008; 30: 201-04.

15. Work PW, Gates GA. Tumors of parapharengeal space. Otolaryngol Clin NAm 1969; Oct: 479-514.

Source of Support: Nil, Conflict of Interest: None Declared 